\title{
Comparative analysis of patient profile, intraoperative characteristics and postoperative outcomes of two routes of hysterectomy: non descent vaginal hysterectomy and total abdominal hysterectomy
}

\author{
Smritee Virmani*, Umarani Swain
}

Department of Obstetrics \& Gynaecology, Sunderlal Jain Hospital, Delhi, India

Received: 07 June 2015

Accepted: 09 July 2015

\author{
*Correspondence: \\ Dr. Smritee Virmani, \\ E-mail: smriteevirmani@yahoo.co.in
}

Copyright: (c) the author(s), publisher and licensee Medip Academy. This is an open-access article distributed under the terms of the Creative Commons Attribution Non-Commercial License, which permits unrestricted non-commercial use, distribution, and reproduction in any medium, provided the original work is properly cited.

\begin{abstract}
Background: Worldwide, hysterectomy is the most common non-pregnancy related major surgery performed on women. In the past, uterine prolapse was the major indication for vaginal route of hysterectomy. However, recently, the applicability of this route has expanded to other common benign gynaecological disorders without uterovaginal descent giving way to non-descent vaginal hysterectomy (NDVH). The purpose of this study was to compare the two routes of hysterectomy: NDVH and TAH.

Methods: The prospective observational study compared fifty cases each undergoing NDVH and TAH respectively for benign gynaecological disorders. Data was statistically analyzed to find out the level of significance between various factors of the two groups.

Results: Most common indication for performing hysterectomy was uterine fibroid (62\%). Large size uteri were removed vaginally by use of complementary techniques. A statistically significant difference was observed in the mean post-operative haemoglobin $(\mathrm{p}=0.03)$ and percentage drop in haemoglobin $(\mathrm{p}=0.000)$ in the two groups. Mean residual pain percentage was more for TAH group $(p=0.000)$, thereby this group required greater number of doses of injectable analgesics $(\mathrm{p}=0.000)$. Duration of catheterization was more for TAH group. The NDVH group showed a faster tolerance to normal diet $(\mathrm{p}=0.000)$ with a faster resumption of normal routine activities $(\mathrm{p}=0.000)$.

Conclusions: Hysterectomy should always be performed by the least invasive and most economical route and NDVH should be a gynecologist's first choice in cases with benign gynaecological disorders.
\end{abstract}

Keywords: Benign gynaecological disorders, Non descent vaginal hysterectomy, Total abdominal hysterectomy

\section{INTRODUCTION}

Worldwide, hysterectomy is the most common nonpregnancy-related major surgery performed on women. The preference to route of hysterectomy depends on a number of clinical and technical factors and it has undergone important changes recently. Various studies in the past have shown that vaginal route of surgery is associated with less febrile morbidity, less bleeding necessitating transfusion, shorter hospitalisation and faster convalescence making it a valid alternative to the abdominal approach.
In the past, uterine prolapse was the major indication for vaginal route of hysterectomy. However, recently, the applicability of this route has expanded to other common benign gynaecological disorders without uterovaginal descent giving way to non-descent vaginal hysterectomy (NDVH) which is removal of uterus through the vaginal route where the position of the uterus is anatomically normal, undescended or first degree descent. Moreover, it is possible to perform NDVH in cases of voluminous uteri by restoring to various complementary methods that permit progressive reduction of the volume of the uteri during surgery like myomectomy, morcellation, corporal bisection, intramyometrial coring. ${ }^{1}$ 
The selection of cases for vaginal or abdominal hysterectomy also depends upon many clinical variables singly or in combination. These include pelvic anatomy, uterine size, adnexal disease, urological disorders (cystocele, rectocele, enterocele), parity, previous caesarean section or pelvic surgery. Despite the fact that vaginal hysterectomy results in less morbidity than abdominal hysterectomy, it is performed infrequently in patients with uteri enlarged by leiomyomas or extensive adenomyosis. However, various studies have shown vaginal hysterectomy to be a valid alternative to the abdominal approach with fewer complications, shorter recovery period and hospital stay. ${ }^{2-4}$ In addition studies also suggest that vaginal hysterectomy can also be performed successfully even in women with an enlarged uterus, nulliparity or history of pelvic surgery and the need for oophorectomy should not be considered a contraindication. ${ }^{5-7}$

With increasing concern over the containment of health care cost, there is a need for expanding the indications for performing NDVH instead of confining to the conventional abdominal approach. Keeping these issues in mind, the present study was conducted to compare characteristics, surgical management and clinical outcomes of patients for the two groups of hysterectomyNDVH and TAH.

\section{METHODS}

This prospective observational study was conducted in a multi-speciality tertiary care centre. We included a total sample of one hundred cases requiring hysterectomy for benign gynaecological disorders in the study and two groups were formed consisting of fifty cases each of NDVH and TAH respectively. These cases were selected on the basis of clinical judgement - factors such as anatomical feasibility, uterine size and mobility, accessibility of lower uterine segment, narrow pubic arch, cervix flushed with vagina- of the operating gynaecologist. Emphasis was laid on the experience of an individual surgeon in performing the surgery; therefore all the procedures were performed by the same surgeon using identical techniques.

Exclusion criteria: Cases with uterovaginal prolapse and malignant conditions of the uterus and the cervix.

Detailed history and a complete general, systemic and pelvic examination were done for all patients with emphasis on the size of uterus, mobility, presence or absence of adnexal mass and uterine descent. USG was performed in all the patients to correlate the clinical diagnosis. Also, all patients underwent a pre-anaesthetic check-up and a pre-surgical counselling to explain the type of surgery and the probable complications involved. A written and informed consent was obtained.

The following observations were noted for the two study groups:

\section{Pre-operative and intra operative:}

1. Demographic characteristics: Age and Parity

2. Ease of dissection and complementary methods used: A note was made regarding the ease of dissection and bringing out of uterus and the various complementary methods viz. morcellation, myomectomy, coring, bisection used during the surgery.

3. Actual uterine weight: The weight of the uterus including other tissues attached with it was measured in the operation theatre using a digital scale.

\section{Post-operative:}

1. Pain perception and dose of analgesics: Pain being a subjective criteria, Visual Analog Scale (VAS) was used to record the residual pain level after giving four doses of injectable analgesics, last dose administered 8 hours prior to grading made by the patient. Injectable analgesics were administered till the patient recorded residual pain as $20 \%$ on VAS. The number of doses of injectable analgesics given to the patient till attaining the residual pain level of $20 \%$ were recorded and compared for the two groups.

2. Hemoglobin estimation: All patients of both the groups had hemoglobin estimation preoperatively and on the second post-operative day. The percentage drop of hemoglobin was calculated for each patient.

3. Duration of catheterization: The duration of Foley's catheterization in hours was recorded for patients of both the groups.

4. Normal diet tolerance: The time taken by the patients of the two groups to tolerate a normal diet in hours was noted.

5. Time to routine activities: The period in weeks were recorded to evaluate the post-operative period for attaining normal routine activities completely and independently. All the cases were advised to follow up after 15 days, one month and three months of discharge. Patients with abdominal hysterectomy were advised for stitch removal on 7 th / 8th post-operative day.

A statistical analysis was performed using SPSS statistical software. All quantitative data were expressed as mean $\pm \mathrm{SD}$. Mean difference in continuous variables were assessed using student's t-test and comparison of categorical variables were made using chi-square tests. A $\mathrm{p}$ value of less than 0.05 was considered to be statistically significant.

\section{RESULTS}

The most common indication for which hysterectomy was performed in the two groups was uterine fibroid 
(62\%). No statistically significant difference was observed in terms of age and parity in the two groups [Table 1]. The mean uterine size for the NDVH group was 6.44 weeks and that for the TAH group was 8.92 weeks, the difference being statistically significant $(\mathrm{p}=0.012)$ [Table 1].

Table 1: Patient characteristics.

\begin{tabular}{|llll|}
\hline & NDVH $(\mathbf{n}=50)$ & TAH $(\mathbf{n}=50)$ & P value \\
\hline $\begin{array}{l}\dagger \text { Age } \\
\text { (years) }\end{array}$ & $44.12 \pm 3.868$ & $44.10 \pm 3.903$ & 0.980 \\
\hline$\dagger$ Parity(no) & $2.32 \pm 0.935$ & $2.26 \pm 0.853$ & 0.726 \\
\hline $\begin{array}{l}\dagger \text { Uterine } \\
\text { weight } \\
\text { (grams) }\end{array}$ & $205.94 \pm 112.717$ & $325.88 \pm 273.466$ & 0.008 \\
\hline $\begin{array}{l}\dagger \text { Uterine } \\
\text { size } \\
\text { (weeks) }\end{array}$ & $6.44 \pm 4.920$ & $8.92 \pm 4.818$ & 0.012 \\
\hline
\end{tabular}

$\dagger$ Mean \pm SD

Largest size uterus removed in the NDVH group was 18 weeks fibroid uterus and that in the TAH group was 24 weeks fibroid uterus. Removal of such large uteri was made possible by use of complementary techniques like morcellation, coring, bisection, myomectomy. These were used in $38 \%$ cases of NDVH and $20 \%$ cases of TAH [Table 2]. Dissection and bringing out of uterus was difficult in $36 \%$ cases of NDVH and $40 \%$ cases of TAH [Table 2]. These were the cases with large uteri with history of previous caesarean delivery. Mean preoperative haemoglobin in the two groups was similar $(\mathrm{p}=0.279)$. However, mean post-operative haemoglobin level in the NDVH group was $10.59 \mathrm{gm}$. \% whereas for the TAH group was $10.11 \mathrm{gm}$. \%, difference being statistically significant $(\mathrm{p}=0.03)$. Furthermore, the percentage drop in haemoglobin was significantly more $(\mathrm{p}=0.000)$ in the TAH group indicating greater blood loss in this group [Table 2].

Table 2: Operative data.

\begin{tabular}{|llll|}
\hline & NDVH $(\mathbf{n}=50)$ & TAH $(\mathbf{n = 5 0 )}$ & P value \\
\hline $\begin{array}{l}\dagger \text { Pre op Hb } \\
\text { (gm. \%) }\end{array}$ & $\begin{array}{l}11.802 \pm \\
0.834\end{array}$ & $12.006 \pm 1.031$ & 0.279 \\
\hline $\begin{array}{l}\dagger \text { Post op Hb. } \\
\text { gm. \%) }\end{array}$ & $10.59 \pm 0.971$ & $10.112 \pm 1.194$ & 0.03 \\
\hline$\dagger \%$ drop in Hb. & $10.32 \pm 4.33$ & $15.85 \pm 6.26$ & 0.000 \\
\hline $\begin{array}{l}\text { Difficult } \\
\text { dissection }\end{array}$ & $36 \%$ & $40 \%$ & \\
\hline $\begin{array}{l}\text { Complementary } \\
\text { techniques used }\end{array}$ & $38 \%$ & $20 \%$ & \\
\hline
\end{tabular}

$\dagger$ Mean \pm SD

With regard to post-operative outcome [Table 3], mean residual pain percentage after surgery was more for the TAH group in comparison to the NDVH group (49.2 vs.
37.4), difference being statistically highly significant $(\mathrm{p}=0.000)$. Also, patients in the NDVH group required lesser number of doses of injectable analgesics when compared with the patients of the TAH group $(\mathrm{p}=0.000)$. The mean duration of catheterization was 29.94 hours for the NDVH group and 49 hours for the TAH group, $(p=0.000)$ [Table 3].The patients in the NDVH group showed a faster tolerance to normal diet in comparison to the patients in the TAH group $(\mathrm{p}=0.000)$ [ Table 3]. After any surgical procedure, a follow up is essential to know the condition of the patient. In the present study, on follow up, mean time taken by the NDVH patients to resume normal routine activities was significantly less $(\mathrm{p}=0.000)$ than that taken by the TAH group ( 4.6 weeks vs. 5.76 weeks) [Table 3].

Table 3: Post-operative outcomes.

\begin{tabular}{|c|c|c|c|}
\hline & $\operatorname{NDVH}(n=50)$ & TAH(n=50) & P value \\
\hline $\begin{array}{l}\dagger \text { Residual pain } \\
\% \text { after } 4 \\
\text { doses of } \\
\text { injectable } \\
\text { analgesics }\end{array}$ & $37.4 \pm 12.257$ & $49.2 \pm 8.291$ & 0.000 \\
\hline $\begin{array}{l}\dagger \text { No. of doses } \\
\text { of injectable } \\
\text { analgesics } \\
\text { required }\end{array}$ & $5.08 \pm 0.877$ & $6.16 \pm 0.509$ & 0.000 \\
\hline $\begin{array}{l}\dagger \text { Duration of } \\
\text { catheterization } \\
\text { (hrs.) }\end{array}$ & $32.16 \pm 8.289$ & $\begin{array}{l}53.32 \pm \\
6.056\end{array}$ & 0.000 \\
\hline $\begin{array}{l}\dagger \text { Tolerance to } \\
\text { normal diet } \\
\text { (hrs.) }\end{array}$ & $44.24+8.653$ & $57.6 \pm 6.963$ & 0.000 \\
\hline $\begin{array}{l}\dagger \text { Time to } \\
\text { routine } \\
\text { activities } \\
\text { (wks.) }\end{array}$ & $4.6 \pm 0.606$ & $5.76 \pm 0.656$ & 0.000 \\
\hline
\end{tabular}

$\dagger$ Mean \pm SD

\section{DISCUSSION}

The optimal route for hysterectomy has always been a subject of extensive discussion. With increasing concern over the containment of health care cost, there is a need for expanding the indications for performing NDVH instead of confining to the conventional abdominal approach in patients with benign gynaecological disorders. The present study was designed and conducted to evaluate and compare NDVH and TAH involving evaluation of all the factors having direct or indirect bearing on the outcome of the study. The main indication for hysterectomy in the two groups was uterine fibroid. Both the groups were comparable in terms of age and parity.

In this study, the mean uterine size for the NDVH group was 6.44 weeks and that for TAH group was 8.92 weeks, difference being statistically significant $(\mathrm{p}=0.012)$. 
Maximum size of uterus removed vaginally was 18 weeks gestational age. In a study carried out by Magos A. et al. ${ }^{6}$ assessing the feasibility and safety of performing vaginal hysterectomy in enlarged uteri, maximum size of uterus removed was 20 weeks, indicating that bigger size of uteri can be removed vaginally and size of uterus should not be considered as a contraindication to vaginal route. In another study by Kore $\mathrm{S}$ et al. ${ }^{4}$ analyzing cases of vaginal hysterectomy for bulky and enlarged uterus of size upto 16 weeks gestation, also concluded that vaginal hysterectomy can be considered even in cases of considerable uterine enlargement. Taking into consideration such large uterine sizes in the present study, various complementary techniques like bisection, coring, myomectomy or a combination of these were applied in $38 \%$ patients of NDVH. This enabled removal of large size uteri vaginally. A similar study carried out by Hoffman et al. ${ }^{8}$ reported that use of complementary procedures enabled removal of moderately enlarged uteri vaginally. Comparative results were also obtained in the study carried out by Kammerer Doak D. et al. ${ }^{9}$ concluding that uterine morcellation at the time of vaginal hysterectomy is safe and facilitates removal of moderately enlarged uteri without increasing peri operative morbidity.

The mean pre-operative haemoglobin level for the two groups NDVH and TAH was 11.802 gram\% and 12.006 gram $\%$ respectively $(\mathrm{p}=0.279)$. The mean post-operative haemoglobin level for NDVH group was 10.59 gram\% and for the TAH group was 10.2 gram $\%$, difference being statistically significant $(\mathrm{p}=0.03)$. So on comparing the percentage drop in haemoglobin level $(\mathrm{p}=0.000)$, it was observed that greater blood loss occurred in patients of TAH group when compared with the NDVH group. In the past, a study carried out by Kayastha et al. ${ }^{10}$ showed a similar result indicating that NDVH is a relatively safe procedure even in enlarged uteri.

In the present study, mean residual pain percentage after administration of four doses of analgesics was 37.4 for NDVH group and 49.2 for TAH group, difference being statistically highly significant $(\mathrm{p}=0.000)$. Also, mean number of doses of injectable analgesics required was less for NDVH group than TAH group $(p=0.000)$. Various studies in the past ${ }^{11-13}$ have also confirmed that patients undergoing vaginal hysterectomy have reduced analgesic requirements when compared with patients undergoing TAH. This not only added to comfort of patients undergoing NDVH but also to the cost effectiveness and early discharge of patients in this group.

In this study, the mean duration of catheterization was 29.94 hours for the patients who underwent NDVH and 49 hours for those who underwent TAH, difference being highly significant statistically $(\mathrm{p}=0.000)$. However, various studies in the past ${ }^{8,12}$ show no statistically significant difference in the mean day of Foley's catheter removal. This could be because there are no standard criteria for timing of Foley's catheter removal as it varies from patient to patient. However in the present study duration of catheterization was less for patients in the NDVH group thereby enabling faster ambulation amongst the group.

In the present study, the mean post-operative day on which the patient was able to tolerate normal diet was 2.56 days for NDVH group and 3.54 days for the TAH group, difference being statistically highly significant $(\mathrm{p}=0.000)$. In a study carried out by Hoffman et al. ${ }^{8}$ patients who underwent vaginal hysterectomy started with regular diet earlier than those who underwent TAH $(\mathrm{p}<0.05)$. Early tolerance to normal diet contributed to early discharge, shorter hospital stay and therefore reduced total cost in the NDVH group. Patients of the two groups were followed up at 15 days, 1 month and 3 months. Follow up showed that patients in the NDVH group resumed their normal routine activities completely and independently, significantly faster than TAH group $(\mathrm{p}=0.000)$. Various studies in literature ${ }^{12,14}$ also state that return back to routine normal activities is faster for vaginal route.

Therefore to summarize, no significant difference was observed in demographic characteristics of the patients of the two groups. Main indication of hysterectomy in both the groups was uterine fibroid. Complementary techniques made removal of large sized uteri through the vaginal route easier with less blood loss. Also, postoperative NDVH patients scored better on Visual Analogue Scale and required lesser doses of injectable analgesics. Period of catheterization was shorter for the NDVH group. Patients in the NDVH group showed a faster tolerance to normal diet and resumed their normal routine activities earlier than those who underwent TAH. Hence, in this orientation, the study supports the fact that NDVH being a minimally invasive procedure should be the technique of choice in routine practice for management of patients with non-malignant pelvic disease involving the uterus.

\section{Funding: No funding sources \\ Conflict of interest: None declared \\ Ethical approval: Not required}

\section{REFERENCES}

1. Kovac SR. Intramyometrial coring as an adjunct to vaginal hysterectomy by uterine morcellation: an efficient, non-morbid procedure. Obstet Gynecol. 1986;67:131-6.

2. Singh A, Bansal S. Comparative study of morbidity and mortality associated with non-descent vaginal hysterectomy and abdominal hysterectomy based on ultrasound determination of uterine volume. Int Surg. 2008;93(2):88-94.

3. Guvenal T, Ozsoy AZ, Kilcik MA, Yanik A. The availability of vaginal hysterectomy in benign gynecologic diseases: a prospective, non-randomized trial. J Obstet Gynecol Res. 2010;36(4):832-7. 
4. Kore S, Sah A, Hedge A, Srikrishna, Ambiye V. Bisection, Myomectomy and Coring in vaginal hysterectomy of large uterus. Bombay Hospital Journal (http://www.bhj.org/journal/1999_4104_oct 99/original_706.htm).

5. Davies A, O' Connor H, Magos AL. A prospective study to evaluate oophorectomy at the time of vaginal hysterectomy. BJOG: An International Journal of Obstetrics and Gynecology. 1996;103:915-20.

6. Magos A, Bournas N, Sinha R, Richardson RE, O' Connor $\mathrm{H}$. Vaginal hysterectomy for the large uterus. Br J Obstet Gynecol. 1996;103(3):246-51.

7. Unger JB, Meeks GR. Vaginal hysterectomy in women with history of previous caesarean delivery. Am J Obstet Gynecol. 1998;179(6):1473-8.

8. Hoffman MS, De Cesare S, Kalter C. Abdominal hysterectomy versus transvaginal morcellation for the removal of enlarged uteri. Am. J Obstet Gynecol. 1994;171:309-15.

9. Kammerer -Doak D, Mao J. Vaginal hysterectomy with and without morcellation: the university of New Mexico hospital's experience. Obstet Gynecol. 1996;88(4):560-3.
10. Kayastha S, Tuladhar H. Vaginal hysterectomy vs. abdominal hysterectomy. Nepal Med Coll J. 2006;8(4):259-62.

11. Benassi I, Rossi T, Kaihura CT, Ricci L, Bedocchi L, Galanti B et al. Abdominal or vaginal hysterectomy for enlarged uteri: A randomized clinical trial. Am J obstet Gynaecol. 2002;187:1561-5.

12. Miskry T, Magos A. Randomized, prospective, double- blind comparison of abdominal and vaginal hysterectomy in women without uterovaginal prolapses. Acta Obstet Gynecol Scand. 2003;82:3518.

13. Dawood NS, Mahmood R, Haseeb N. Comparison of vaginal and abdominal hysterectomy: peri and postoperative outcome. J Ayub Med Coll Abbottabad. 2009;21(4):116-20.

14. Johnson N, Barlow D, Lethaby A, Tavender E, Curr L, Garry R. Methods of hysterectomy: systemic review and meta-analysis of randomized controlled trials. BMJ. 2005,330:1478.

Cite this article as: Virmani $\mathrm{S}$, Swain $\mathrm{U}$. Comparative analysis of patient profile, intraoperative characteristics and postoperative outcomes of two routes of hysterectomy: non descent vaginal hysterectomy and total abdominal hysterectomy. Int J Reprod Contracept Obstet Gynecol 2015;4:1128-32. 